\title{
Isolation of microsatellite DNA markers from a passerine bird, Dendroica petechia (the yellow warbler), and their use in population studies
}

\author{
ROBERT J. G. DAWSON $+\neq, H$. LISLE GIBBS*+, KEITH A. HOBSON§ \& STEPHEN M. \\ YEZERINACI \\ $\nmid$ Department of Biology, McMaster University, 1280 Main Street West, Hamilton, Ontario, Canada, L8S 4K1, §Prairie \\ and Northern Research Centre, Canadian Wildlife Service, 115 Perimeter Road, Saskatoon, Saskatchewan, Canada, \\ S7N 0X4 and IDepartment of Biology, Carleton University, Ottawa, Ontario, Canada, K1A 3N6
}

\begin{abstract}
We describe the isolation and genetic characterization of five microsatellite loci in a passerine bird, the yellow warbler Dendroica petechia, and assess their use for various types of population-level analysis using data from two breeding populations. All five loci show levels of variability comparable to those observed in other vertebrates $\left(H_{\exp }=0.388-0.989\right)$. One locus, $D p \mu 05$, is highly variable with 46 alleles detected in 41 individuals. All loci appeared to segregate in a Mendelian fashion as judged by patterns of inheritance in known families. However, one locus showed a significant heterozygote deficiency in one population suggesting the possible presence of null alleles at this locus. These markers provide a highly accurate system for determination of parentage in this species: the probability of detecting extrapair fertilization by males given known maternity was 0.999 in each of two separate populations. Comparison of allele frequencies and genetic distances between the two populations showed no evidence for significant differences in allele frequencies at individual loci, whereas the overall genetic distance and $F_{\mathrm{ST}}$-value are significantly different from zero suggesting weak differentiation. Finally, cross-species amplification experiments showed that at least one locus appears to amplify products in a wide range of birds including nonpasserine species. Thus, our results demonstrate that these loci will provide a useful set of genetic information for addressing a wide range of population-level analyses in this and other bird species.
\end{abstract}

Keywords: genetic differentiation, microsatellite DNA markers, migratory birds, parentage analysis, population studies.

\section{Introduction}

Genetic markers which show a high level of intraspecific variation are useful tools for addressing a wide range of important issues in population biology (Avise, 1994); for example, depending on the level of variability and genetic characteristics, markers of this type can be used to examine a broad range of questions concerning parentage and kinship, population differentiation and estimation of population genetic parameters, such as gene flow and effective

*Correspondence, E-mail: gibbs@mcmail.cis.mcmaster.ca

†Present address: Division of Environmental and Evolutionary Biology, University of Glasgow, Glasgow G12 8QQ, U.K. population size (cf. Quellar et al., 1993). Molecular biology techniques have been an important source of such highly variable DNA markers, including RAPDs, mitochondrial and nuclear sequence data, and multi- and single-locus minisatellites (for review see Avise, 1994). However, each of these types of marker can have significant methodological or logistic disadvantages which prevent their application to a particular population study. As described by Quellar et al. (1993), the ideal marker would have distinguishable loci with codominant alleles which may be unambiguously identified and, furthermore, such information would be logistically relatively easy to obtain. Recently discovered microsatellite DNA 
loci (Tautz, 1989; Weber \& May, 1989) come as close as any currently available marker system to meeting these criteria.

The basis for allelic variation in microsatellite loci is size variation owing to differences in the number of a simple (1-10 base pairs) tandem repeat. Most commonly, repeats of $2-5$ base pairs have been identified in vertebrates. Microsatellite DNA seems to be relatively abundant in the genomes of many taxa and loci have been isolated from a variety of wild vertebrates including pilot whales (Amos et al., 1992), wombats (Taylor et al., 1994), black bears (Paetkau \& Strobeck, 1994) and a number of avian species (Ellegren, 1992; Hanotte et al., 1994; McDonald \& Potts, 1994; Primmer et al., 1995; Gibbs et al., 1996). In birds, these markers have been used primarily for parentage analysis (cf. Primmer et al., 1995) with much less effort devoted to assessing the use of these markers for other purposes such as population differentiation (but see Gibbs et al., 1996). Analysis of markers from additional bird species would be useful, not only to assess their general use for population studies in birds but also to make available additional loci for possible use in other species.

In this paper, we describe the isolation and genetic characterization of five microsatellite loci which have been cloned from a neotropical migratory songbird, the yellow warbler Dendroica petechia. We show that such markers can be used to assess parentage to a high degree of certainty in this species and also how they can be used to assess levels of differentiation among breeding populations of yellow warblers. Thus, our results provide a comprehensive assessment of the value of such markers for a variety of types of population studies in birds.

\section{Materials and methods}

\section{Isolation and characterization of microsatellite loci}

To isolate microsatellite DNA loci from yellow warblers we first constructed an enriched plasmid library following the general approach of Rassman et al. (1991). Briefly, $10 \mu \mathrm{g}$ of DNA from a single female was digested with $10 \mathrm{U}$ each of $A l u \mathrm{I}$, HaeIII and RsaI. Size fragments $250-450 \mathrm{bp}$ in length were then purified from an agarose gel and cloned into the SmaI site of pUC18 plasmid vector using a ratio of $3: 1$ (insert:vector) in the ligation mixture. This library was then transformed into XL1-Blue (Stratagene) competent cells and plate lifts made using Hybond-N (Amersham) nylon membranes. To identify colonies with plasmids containing possible microsatellite sequences, these membranes were screened by hybridizing filters with probes made by labelling three dinucleotide polymer tracts $(\mathrm{TG})_{n}$, $(\mathrm{TC})_{n}$ and $(\mathrm{GC})_{n}$ (Pharmacia) v ith alpha ${ }^{32} \mathrm{P}$-dCTP using random priming. Positive colonies identified in the first round of screening were restreaked and screened a second time. Primary and secondary screening of roughly 8000 colonies yielded a total of 18 positive clones.

Once colonies containing positive clones were identified, they were grown up in $5 \mathrm{~mL}$ of Terrific Broth (Tartof \& Hobbs, 1987), plasmid DNA isolated by alkaline lysis and the inserts sequenced using conventional dideoxy (Sequenase 2.0) or cycle sequencing (AmpliTaq) protocols. We then used the program PRIMER (Ver. 0.5; Lincoln et al., 1991) to identify suitable primers and appropriate annealing temperatures $\left(T_{\mathrm{m}}\right)$ for amplifying regions containing a microsatellite repeat.

\section{PCR amplification and genotyping of individuals}

To assay variation among individuals for specific loci, PCR reactions were performed in $10 \mu \mathrm{L}$ volumes which contained $50 \mathrm{ng}$ of genomic DNA, $0.4 \mathrm{pmol}$ of the forward primer labelled with $\mathrm{P}^{33}$-dATP, 0.4 pmol of unlabelled forward primer, $0.8 \mathrm{pmol}$ of unlabelled reverse primer, $200 \mu \mathrm{m}$ dNTPs, $0.5 \mathrm{U}$ AmpliTaq, $0.1 \mathrm{~m}$ Tris- $\mathrm{HCl} \mathrm{pH} 8.3$, $0.5 \mathrm{M} \mathrm{KCl}, 0.001$ per cent $\mathrm{w} / \mathrm{v}$ gelatine, and $1.5-2.0 \mathrm{~mm} \mathrm{MgCl}_{2}$. Following an initial denaturing step at $94^{\circ} \mathrm{C}$ for $3 \mathrm{~min}, 30$ cycles of PCR were carried out, each cycle consisting of $30 \mathrm{~s}$ at $94^{\circ} \mathrm{C}$, $30 \mathrm{~s}$ at $T_{\mathrm{m}}$ in Table 1 and $30 \mathrm{~s}$ at $72^{\circ} \mathrm{C}$. Amplification products were resolved on 6 per cent polyacrylamide denaturing gels containing $7.7 \mathrm{~m}$ urea. Gels were run at $55 \mathrm{~W}$ for $2-3 \mathrm{~h}$. Where possible, products were double- or triple-loaded. Dried gels were exposed to BIOMAX (Dupont) X-ray film overnight. Product sizes were determined by reference to a sequencing reaction of a known template, and a clone of known size for each locus run every five lanes.

\section{Population samples}

To assess levels of variation detected by the microsatellite loci selected, we used DNA samples obtained from adult yellow warblers captured while breeding in two geographically discrete populations. The first was at the Queen's University Biology Station, Chaffey's Locks, Ontario and is representative of the Great Lakes-St. Lawrence forest region, 
Table 1 Summary of the genetic characteristics of seven yellow warbler microsatellite loci. Product sizes given (bp) are those derived from each respective clone sequence. Mean allele frequencies are given $\pm 1 \mathrm{SD}$

\begin{tabular}{lllccc}
\hline Name & Repeat motif & Primer sequence & $\begin{array}{c}\text { Product } \\
\text { size }\end{array}$ & $\begin{array}{c}\text { No. alleles } \\
\text { (no. individuals) }\end{array}$ & $\begin{array}{c}\text { Mean } \\
\text { frequency }\end{array}$ \\
\hline$D p \mu 01$ & $(\mathrm{CA})_{22}$ & $\begin{array}{l}\text { F-TGGATTCACACCCCAAAATT } \\
\text { R-AGAAGTATATAGTGCCGCTTGC }\end{array}$ & 166 & $22(46)$ & $0.045 \pm 0.037$ \\
$D p \mu 03$ & $*(\mathrm{GAGg} / \mathrm{cA})_{5}(\mathrm{GAGAGGa} / \mathrm{g})$ & $\begin{array}{l}\text { F-GAATTACCCATTATTGGATCC } \\
\text { R-AGCAGCAAAACAAACCAG }\end{array}$ & 150 & $7(48)$ & $0.143 \pm 0.30$ \\
$D p \mu 05$ & $(\mathrm{GAAGA})_{21}$ & $\begin{array}{l}\text { F-GGTCTGTGCTCTGTATGG } \\
\text { R-TCTGAATATTGAACAGCCTA }\end{array}$ & 169 & $46(41)$ & $0.022 \pm 0.016$ \\
$D p \mu 15$ & $(\mathrm{AC})_{12} \mathrm{AT}(\mathrm{AC})_{2}$ & $\begin{array}{l}\text { F-GGCTGCAAACTCATTATCTC } \\
\text { R-ATTGAGTCTGTCAGGTCCAG }\end{array}$ & 159 & $18(50)$ & $0.056 \pm 0.80$ \\
$D p \mu 16$ & $(\mathrm{AC})_{12}(\mathrm{GC})_{4} \mathrm{ACGCAC}(\mathrm{GC})_{2}$ & $\begin{array}{l}\text { F-ACAGCAAGGTCAGAATTAAA } \\
\text { R-AACTGTTGTGTCTGAGCCT }\end{array}$ & 162 & $18(48)$ & $0.056 \pm 0.042$ \\
& & & & & \\
\hline
\end{tabular}

*Full sequence of the repeat at this locus is

$(\text { GAGGA) })_{2}(\text { GAGAGGA) })_{3}(\text { GAGAGGG)(GAGAGGA)(GAGCA) })_{2}($ GAGGA)(GAGAGGA).

whereas the second was at the University of Manitoba Field Station, Delta Marsh, Manitoba, which is a beech-aspen grove and marsh habitat. The two sites are situated $\approx 2000 \mathrm{~km}$ apart at latitudes near $45^{\circ} \mathrm{N}$ and $51^{\circ} \mathrm{N}$, respectively, in southern Canada. Details of the techniques used to capture, collect blood samples from, and extract high quality DNA from each bird are given in Yezerinac et al. (1995). Samples from approximately 30 birds from each site were used. In addition, samples of five confirmed monogamous families, determined using multilocus DNA fingerprinting (Yezerinac et al., 1995), were obtained to examine the segregation characteristics of the microsatellite loci described here.

\section{Results}

\section{Identification of microsatellite loci}

Based on sequences from positive clones, we identified six primer pairs which consistently amplified scorable products from genomic DNA. One primer set appeared to amplify a female-specific fragment; details of its sequence and usefulness as a sex-specific marker will be reported elsewhere (R. J. G. Dawson et al., unpublished information). Table 1 shows the primer sequences and the genetic characteristics of the five other microsatellite loci that detected polymorphic products. The highest degree of 'stutter' was observed with $D p \mu 01$, a pure $(\mathrm{CA})_{n}$ repeat. Other 'cryptically simple' or 'imperfect' repeats (Tautz, 1989; Weber, 1990) such as $D p \mu 15$ and $D p \mu 16$ gave more clearly interpretable patterns; for example, $D p \mu 15$ represents an $(\mathrm{AC})_{14}$ repeat interrupted by a single AT dinucleotide and characteristically exhibits a single, smaller stutter band.

\section{Levels of variability}

To estimate levels of variation at each microsatellite locus, we surveyed 50 unrelated yellow warblers divided among two populations, and two birds from southern Ontario. Not all individuals were screened for all loci. Several loci are highly polymorphic (Table 1$)$. The least variable locus $(D p \mu 03)$ has only seven alleles among 48 individuals with a mean allele frequency of 0.143 , whereas the most variable locus $(D p \mu 05)$ has 46 alleles among 41 individuals with a mean allele frequency of 0.0217 . Examples of genotype profiles obtained using three of the loci are shown in Fig. 1.

\section{Patterns of inheritance}

To be useful for population studies, microsatellite alleles must be inherited in a Mendelian manner. Segregation characteristics at each locus were determined using five yellow warbler families of known parentage. For each microsatellite locus, alleles appeared to be inherited in a Mendelian manner: all offspring share one allele with the paternal and one with the maternal genotype (Fig. 2). This was even the case for the hypervariable $D p \mu 05$, where one female had two alleles that differed by only a single base pair. In two instances for two loci, both parents shared the same genotype. Thus far, we have screened 100 offspring in total for five loci, and therefore 200 meiotic events without observing a 
mutation. At no locus is there evidence for the existence of null (nonamplifying) alleles (sensu Pemberton et al., 1995; Primmer et al., 1995), at least based on segregation patterns observed in families where both parents are heterozygous (but see below).

\section{Use of microsatellite markers for parentage analysis}

To assess the usefulness of these loci for parentage analysis we calculated the probability of detecting stray paternal alleles in offspring ( $\mathrm{P}[\mathrm{E}]$ ) using the formula in Chakravarti \& $\mathrm{Li}$ (1983). This analysis assumes that maternity of the offspring is known and uses allele frequencies to estimate the probability of detecting the occurrence of an extrapair fertilization by an additional male or a female for a given pair.
Table 2 shows the $\mathrm{P}[\mathrm{E}]$-values for the five microsatellite loci in each of the two populations (Ontario and Manitoba). The importance of high variability for this analysis is clearly demonstrated by these data. For $D p \mu 03$, where there are seven alleles in the Ontario population but only three in the Manitoba population, the probability of exclusion in the former is strengthened fivefold (to a value of 0.271 ) by the presence of just over twice the number of alleles. Values for each locus are otherwise similar in the two populations and range from a low of 0.054 for the relatively invariant $D p \mu 03$ in Manitoba to a high of 0.920 for the highly variable $D p \mu 05$ in Ontario. Pooling the values for all loci produces an overall value for $\mathrm{P}[\mathrm{E}]$ of 0.9990 for the Manitoba population and 0.9993 for the Ontario population. When all information from both populations is

Fig. 1 Patterns of microsatellite alleles following amplification at three loci: (a) $D p \mu 01$, (b) $D p \mu 05$ and (c) Dp $\mu 16$.

(a)

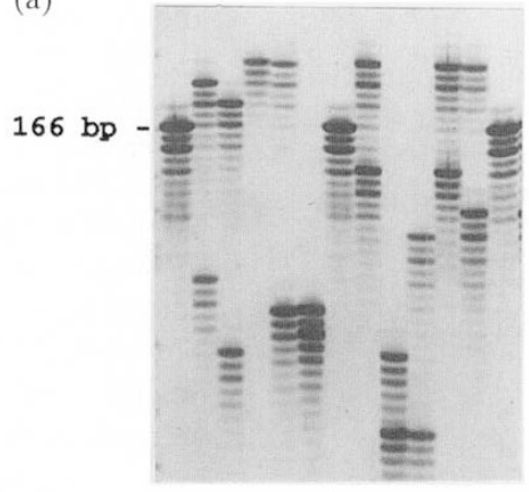

(b)

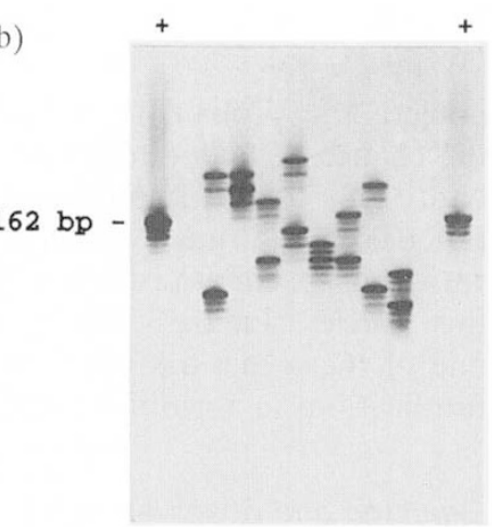

(c)

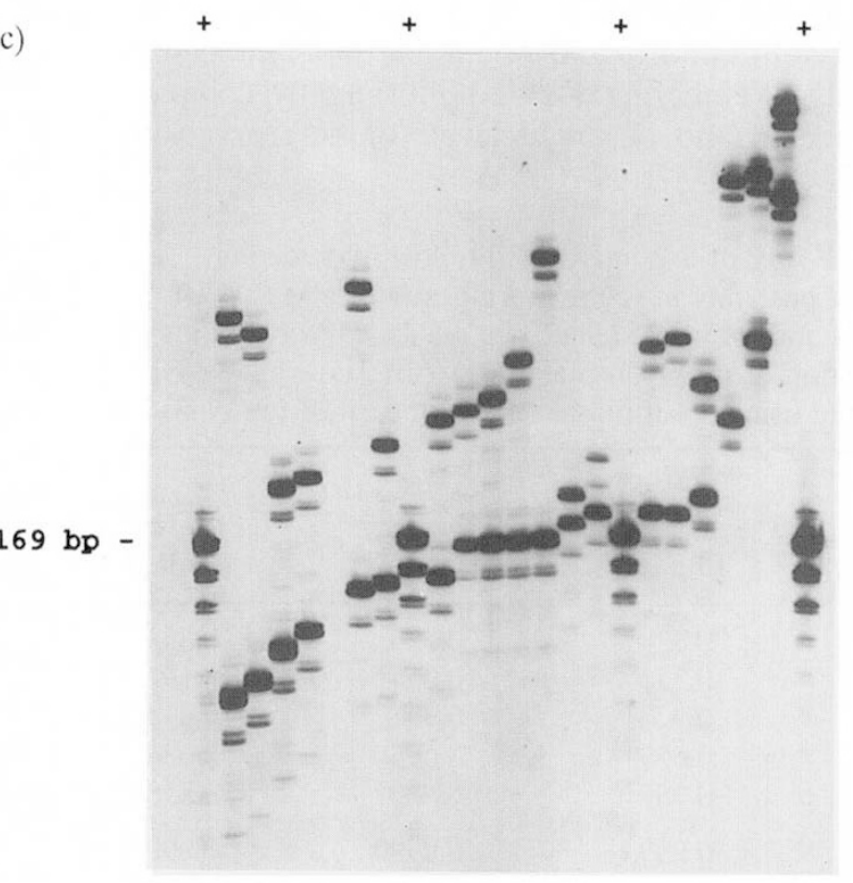

(c) The Genetical Society of Great Britain, Heredity, 79, 506-514. 


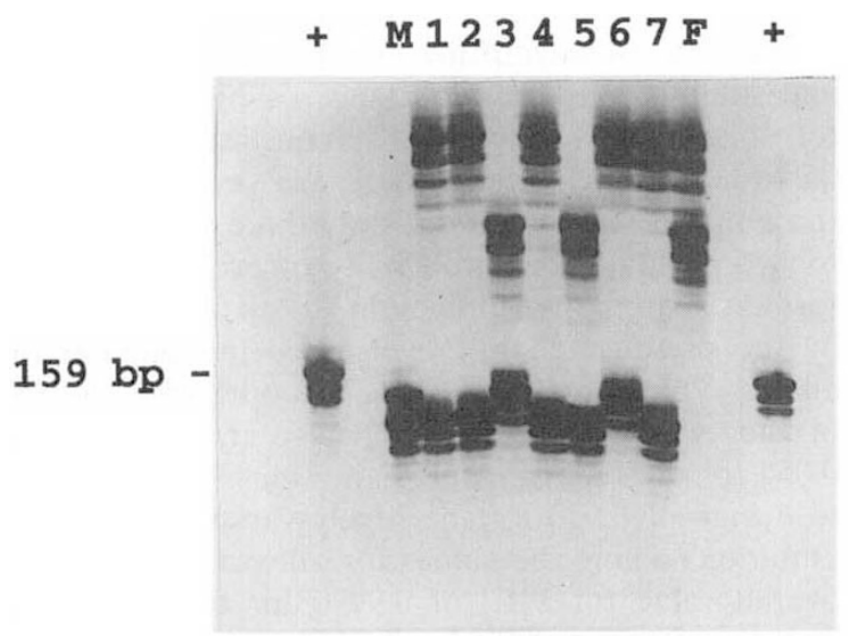

Fig. 2 Inheritance of microsatellite alleles at the locus Dp $\mu 15$ in a known true family of yellow warblers. Each offspring $(1-7)$ receives one allele from each parent. The size of the clone in base pairs (bp) is shown.

pooled, the probability is 0.9996 . This means that the chance of failing to detect extrapair paternity in both of these populations is extremely low $(P<0.001)$ and thus five loci alone provide sufficient variation for high-resolution parentage analysis in this species. Figure 3 shows an example of where one of these loci has been used to detect extrapair fertilizations in a warbler family.

\section{Expected and observed levels of heterozygosity}

We assessed whether genotypic variation at each locus in both Ontario and Manitoba populations was in Hardy-Weinberg (HW) equilibrium by comparing expected and observed levels of heterozygosity

Table 2 Power of five microsatellite loci in detecting extrapair paternity in yellow warbler families at each of two sites and for pooled allele frequencies. Probabilities of detection of stray paternal alleles (P[E]) were calculated using the formula of Chakravarti \& $\mathrm{Li}(1983)$

\begin{tabular}{llcl}
\hline & \multicolumn{3}{c}{ Values of P[E] } \\
\cline { 2 - 4 } Locus & Ontario & Manitoba & Pooled \\
\hline$D p \mu 01$ & 0.834 & 0.824 & 0.853 \\
$D p \mu 03$ & 0.271 & 0.054 & 0.194 \\
$D p \mu 05$ & 0.920 & 0.901 & 0.934 \\
$D p \mu 15$ & 0.659 & 0.665 & 0.686 \\
$D p \mu 16$ & 0.787 & 0.820 & 0.828 \\
All loci & 0.9993 & 0.9990 & 0.9996 \\
\hline
\end{tabular}

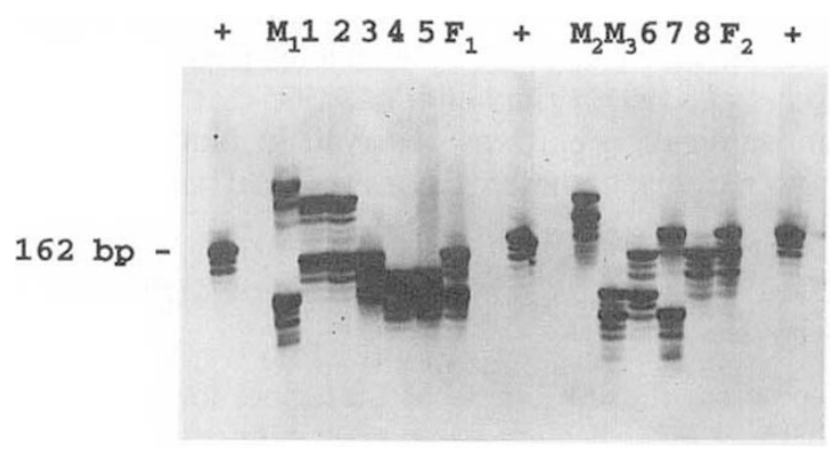

Fig. 3 Extrapair fertilizations detected using microsattellite locus $D p \mu 16$. Selected genotypes from two families are shown. In Family 1, each offspring (1-5) inherits one maternal allele but none from the male. This is repeated in Family 2 (see offspring 6-8). A candidate bird, $\mathrm{M}_{3}$, is supported as the cuckolding male in Family 2. An amplification of the $D p \mu 16$ clone is included as an internal size standard.

and by calculating $F_{\mathrm{IS}}$-values for each locus (Table $3)$. For the Ontario population, no loci showed evidence for a significant heterozygote deficit and all

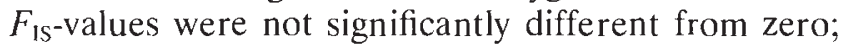
these loci appear to be in HW equilibrium. In the Manitoba population, only one locus (Dp $\mu 15)$ showed a significant reduction in the number of heterozygotes and a positive significant $F_{\mathrm{IS}}$-value. The overall $F_{1 S}$-value, pooled across all loci is also positive (0.126) and highly significant, probably because of the large effect of $D p \mu 15$.

\section{Population differentiation}

We compared allele frequencies among the two populations using: (i) the contingency table analysis described by Roff \& Bentzen (1989), which uses a randomization procedure for hypothesis testing; and (ii) the exact tests for allelic differentiation described by Raymond \& Rousset (1995). Results of both analyses are shown in Table 4. No locus shows a significant difference in allele frequencies between the populations for either test, although results for some loci approach significance. When results across all loci are pooled, the overall probability that the allele frequencies differ among the populations is also not statistically significant although the overall value obtained for the exact test is close to significance $(P=0.074)$. Despite this lack of differentiation, we note that a significant number of alleles are unique to a given population (Table 5). Between 35 per cent and 65 per cent of alleles are shared, and the Ontario population has a conspicuously higher average number of unique alleles per locus. The 
presence of these unique alleles may result from the comparatively small sample sizes, the small number (two) of populations examined and the high degree of polymorphism exhibited by these loci.

Values for Nei's genetic distance $(D ; \mathrm{Nei}, 1987)$ and the fixation index, $F_{\mathrm{ST}}$, are shown in Table 6 . The overall $D$-value was 0.048 and is significantly different from zero based on the fact that the 95 per cent confidence interval does not contain zero. The $F_{\mathrm{ST}}$-value for only one locus $(D p \mu 03)$ is significantly different from zero but the overall $F_{\mathrm{ST}}$-value (0.0099) is significant $(P=0.034)$ and indicates that, on average, 1 per cent of the variation in each of the five loci is unique to each population. Overall, these values suggest weak genetic differentiation between these populations.

\section{Cross-species amplification of microsatellites}

Cross-species amplification of yellow warbler microsatellites was attempted using a panel of two individuals of each of eight species spanning the passeriform and cuculiform orders. Success of crosshybridization was judged by the presence of an expected-size product following a PCR amplification using a uniform annealing temperature of $50^{\circ} \mathrm{C}$. The ability of different primer sets to amplify fragments in other species was variable. However, one locus, $D p \mu 16$, successfully amplified all species surveyed (Fig. 4).

\section{Discussion}

Our primary result is that we have identified a set of microsatellite markers in a passerine bird which appear to be highly polymorphic and, therefore, of use for addressing a variety of population-level genetic issues in this and other species through the use of conserved loci. We comment on issues related to various applications below.

\section{Value for parentage studies}

Ellegren (1992) and Primmer et al. (1995) have reviewed the uses of microsatellite loci for parentage studies in birds. We add only that our results support their findings in that they demonstrate that a relatively small number of loci - particularly those highly polymorphic ones such as $D p \mu 05$ - have powers of resolution for parentage analysis that may

Table 3 Expected and observed heterozygosity, and $F_{15}$-values for five microsatellite loci in (a) Ontario and (b) Manitoba populations of yellow warblers. $H_{\exp }$ is calculated as described by Nei \& Roychoudhury (1974); $H_{\mathrm{obs}}$ is the proportion of the individuals in the sample which are heterozygotes. $n$ is the number of birds genotyped. Overall heterozygosity values are means of values for each locus. $F_{1 \mathrm{~S}}$ is calculated as described by Weir \& Cockerham (1984). $P_{\mathrm{h}}$-values are for significance of difference between observed and expected number of heterozygotes as tested using the exact test described in GENEPOP (Raymond \& Rousset, 1995), whereas $P_{\mathrm{f}}$-values are the probability that the $F_{\mathrm{Is}}$-values were different from zero tested using permutation procedures in FSTAT (Goudet, 1995)

\begin{tabular}{lccccrc}
\hline Locus & $n$ & $H_{\text {exp }}$ & $H_{\text {obs }}$ & $P_{\mathrm{h}}$ & \multicolumn{1}{c}{$F_{\mathrm{IS}}$} & $P_{\mathrm{f}}$ \\
\hline (a) Ontario & & & & & & \\
$D p \mu 01$ & 26 & 0.935 & 0.923 & 0.437 & 0.013 & 0.510 \\
$D p \mu 03$ & 30 & 0.453 & 0.500 & 0.892 & -0.107 & 0.947 \\
$D p \mu 05$ & 21 & 0.985 & 0.952 & 0.475 & 0.034 & 0.266 \\
$D p \mu 15$ & 30 & 0.831 & 0.800 & 0.070 & 0.037 & 0.387 \\
$D p \mu 16$ & 23 & 0.456 & 0.419 & 0.059 & 0.099 & 0.093 \\
Overall & & 0.732 & 0.719 & & 0.029 & 0.130 \\
(b) Manitoba & & & & & & \\
$D p \mu 01$ & 20 & 0.933 & 0.900 & 0.473 & 0.037 & 0.387 \\
$D p \mu 03$ & 18 & 0.110 & 0.111 & 1.000 & -0.015 & 0.999 \\
$D p \mu 05$ & 20 & 0.976 & 0.950 & 0.494 & 0.053 & 0.086 \\
$D p \mu 15$ & 20 & 0.850 & 0.555 & 0.007 & 0.359 & 0.001 \\
$D p \mu 16$ & 23 & 0.935 & 0.850 & 0.130 & 0.093 & 0.163 \\
Overall & & 0.761 & 0.673 & & 0.126 & 0.001 \\
\hline
\end{tabular}


approach those of hypervariable minisatellite markers. Our study also shows that this capacity is similar among different populations of the same species.

Once markers are cloned, two major advantages of using PCR-based techniques for parentage and other genetic analyses are their reduced cost and increased speed; for example, based on cost comparisons in our laboratory for the genotyping of individuals using multilocus minisatellite probes (cf. Gibbs et al., 1994) vs. microsatellite loci, we estimate that on a genotype-per-individual basis, a microsatellite profile costs less than one-tenth the amount required to produce an individual DNA fingerprint. Although additional microsatellites are required for equivalent resolving power, the five loci in this study still provide an overall $\mathrm{P}[\mathrm{E}]$-value of 0.9996 , which would be sufficient for parentage resolution in populations of typical size for this species (cf. Yezerinac

Table 4 Analysis of allele frequencies in two breeding populations of yellow warblers using contingency table analyses and exact tests. $P(\mathrm{~h})$, the probability of homogeneity of allele frequencies, was calculated using the program CHIRxC (Zaykin \& Pudovkin, 1993). The $95 \%$ confidence interval is based on 1000 permutations. The overall $\chi^{2}$-value, which combines $P$-values across loci, is calculated as described by Sokal \& Rohlf (1981; p. 780). $P(\mathrm{e})$ is based on an exact test which estimates the probability that allele frequencies differ between populations and is calculated using GENEPOP also based on 1000 permutations

\begin{tabular}{lccc}
\hline Locus & $\chi^{2}$ (d.f.) & $P(\mathrm{~h}) \pm 95 \% \mathrm{CI}$ & $P(\mathrm{e})$ \\
\hline$D p \mu 01$ & $24.94(21)$ & $0.212 \pm 0.025$ & 0.210 \\
$D p \mu 03$ & $8.62(6)$ & $0.168 \pm 0.005$ & 0.173 \\
$D p \mu 05$ & $41.40(45)$ & $0.817 \pm 0.023$ & 0.830 \\
$D p \mu 15$ & $22.73(17)$ & $0.102 \pm 0.020$ & 0.069 \\
$D p \mu 16$ & $22.67(17)$ & $0.108 \pm 0.100$ & 0.100 \\
Overall & $16.10(10)$ & $>0.05$ & 0.074 \\
\hline
\end{tabular}

et al., 1995) and would be produced at less than half the cost of conventional fingerprints. Additionally, a microsatellite genotype can be generated and scored in 2 days, whereas a multilocus fingerprint can take up to 3 weeks to produce. Therefore, in our opinion (pending availability) the reduced cost and increased speed of production, combined with the analytical advantages of using single- vs. multilocus genotypic information, make microsatellites the method of choice for parentage analysis.

One potential drawback to the use of at least some of these loci for parentage analyses and other types of population studies is that the presence of significant heterozygote deficiencies at specific loci (e.g. $D p \mu 15)$ may indicate the presence of null or nonamplifying alleles at these loci, which are the result of mutations in the primer sites in different individuals (cf. Pemberton et al., 1995; Brookfield 1996). When such mutations occur, an individual who is a heterozygote but who has a null allele, will be scored as a homozygote because only one of the two alleles present will be amplified. This can result in false exclusions of such individuals as potential parents and inaccurate estimates of the frequencies of specific alleles in populations. One way to identify null alleles is to construct alternative primer sets which flank the repetitive sequence but do not overlap the locations of the original primer sets and then to regenotype all individuals who were originally classified as homozygotes. If this procedure does not result in a reclassification of such individuals as heterozygotes (see, for example Gibbs et al., 1997), then a biological explanation (e.g. local inbreeding) may be sought for the heterozygote deficiency.

\section{Population differentiation}

The information on distances and differences in allele frequencies suggests that the Ontario and Manitoba yellow warbler populations are weakly genetically differentiated and that a high level of

Table 5 Numbers of shared and unique alleles at each of five microsatellite loci among two breeding populations of yellow warblers

\begin{tabular}{lccc}
\hline Locus & $\begin{array}{c}\text { Total number } \\
\text { of alleles }\end{array}$ & $\begin{array}{c}\text { \% Shared alleles } \\
\text { between populations }\end{array}$ & $\begin{array}{c}\text { Number of } \\
\text { unique alleles } \\
\text { (Ontario/Manitoba) }\end{array}$ \\
\hline $\mathrm{Dp} \mu 01$ & 22 & 63.6 & $6 / 2$ \\
$\mathrm{D} \mu 03$ & 7 & 42.8 & $4 / 0$ \\
$\mathrm{D} \mu 05$ & 46 & 34.6 & $17 / 13$ \\
$\mathrm{D} \mu 15$ & 18 & 44.6 & $7 / 3$ \\
$\mathrm{D} \mu 16$ & 18 & 66.7 & $3 / 3$ \\
\hline
\end{tabular}


Table 6 Genetic distances (Nei's $D$ ) and fixation indices $\left(F_{\mathrm{ST}}\right)$ based on comparisons of microsatellite allele frequencies in the Manitoba and Ontario yellow warbler populations. $D$-values were calculated using the program MICROSAT (Minch et al., 1995). The SE for the overall $D$-value is based on 1000 bootstrapped values across all five loci. The individual estimates and $P$-values for $F_{\mathrm{ST}}$ were generated using FSTAT

\begin{tabular}{lccc}
\hline Locus & $D$ & $F_{\mathrm{ST}}$ & $P$ \\
\hline$D p \mu 01$ & 0.074 & 0.00448 & 0.237 \\
$D p \mu 03$ & 0.005 & 0.0656 & 0.002 \\
$D p \mu 05$ & 0.001 & -0.00373 & 0.737 \\
$D p \mu 15$ & 0.081 & 0.0115 & 0.175 \\
$D p \mu 16$ & 0.095 & 0.0073 & 0.222 \\
Overall & $0.048 \pm 0.024 \mathrm{SE}$ & 0.0099 & 0.034 \\
\hline
\end{tabular}

gene flow (estimated $\mathrm{Nm}$ based on overall $F_{\mathrm{ST}}$-value $>25$ ) occurs between them. Contrary to these results is our observation that a substantial number of the alleles at different loci are unique to particular populations (Table 5). These have little impact on estimates of differentiation owing to their low frequency, but their presence could be interpreted as the result of new alleles accumulating in recently diverged but genetically isolated populations. Alternatively, they may be widespread at low frequencies and consequently missed because of sampling effects, so perhaps should not be regarded as 'private' alleles. Additional sampling of more individuals from these and other warbler popula-

\section{AR OV ST BC CU SA Ph}

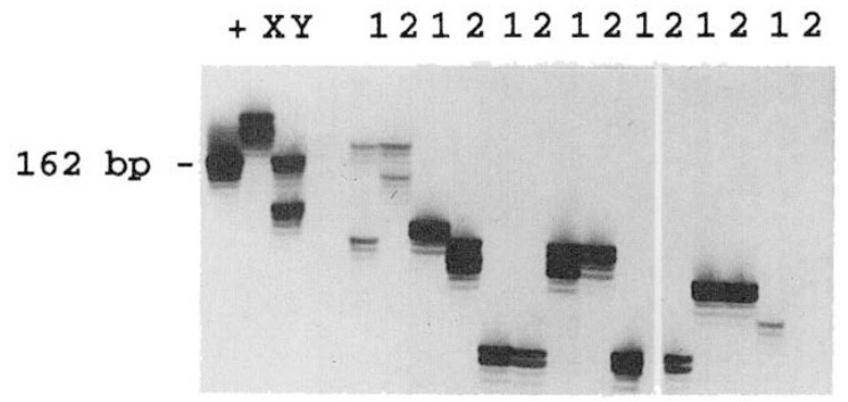

Fig. 4 Cross-species amplification at microsatellite locus Dp $\mu 16$. X and $\mathrm{Y}$ represent yellow warblers of known genotype. The clone amplification is represented by + . Other species are: AR, American redstart, Setophaga ruticilla; OV, ovenbird, Seiurus aurocapillus; ST, Swainson's thrush, Catharus ustulatus; BC, brown-headed cowbird, Molothrus ater; $\mathrm{CU}$, common cuckoo, Cuculus canorus; SA, smooth-billed ani, Crotophaga ani; Ph, Phylloscopus sp.

(c) The Genetical Society of Great Britain, Heredity, 79, 506-514. tions will help discriminate between these alternatives. To address this and other issues related to population differentiation, we are currently conducting a continent-wide survey of this and other migratory passerines to determine the extent to which population genetic structure is found, and the geographical scale at which it may exist.

\section{Acknowledgements}

We thank Liliana DeSousa and especially Gerry Alderson for help with the laboratory work, Lisa Tabak for perfecting the figures, Trevor Price and Brian Golding for assistance with data analysis, and Trevor Price and Jim Quinn for comments and discussion. This research was supported by a grant from the Max Bell Foundation, a contract from the Environmental Innovation Program, Environment Canada, and an NSERC Research Grant to H.L.G.

\section{References}

AMOS, B., SCHLÖTTERER, C. AND TAUTZ, D. 1992. Social structure of pilot whales revealed by analytical DNA profiling. Science, 260, 670-672.

Avise, J. C. 1994. Molecular Markers, Natural History and Evolution. Chapman and Hall, London.

BROOKFIELD, J. F. Y. 1996. A simple method for estimating null allele frequency from heterozygote deficiency. Mol. Ecol., 5, 453-455.

CHAKRAVARTI, A. AND L1, c. c. 1983. The effect of linkage on paternity calculations. In: Walker, R. H. (ed.), Inclusion Probabilities in Parentage Testing pp. 411-422. American Association of Blood Banks, Arlington, VA.

Ellegren, H. 1992. Polymerase chain reaction (PCR) analysis of microsatellites - a new approach to the study of genetic relationships in birds. Auk, 109, 886-895.

GIBBS, H. L., GOLDIZEN, A. W., BULLOUGH, C. AND GOLD1ZEN, A. R. 1994. Parentage analysis of multi-male social groups of Tasmanian native hens (Tribonyx mortierii): genetic evidence for monogamy and polyandry. Behav. Ecol. Sociobiol., 35, 363-371.

GIBBS, H. L., BROOKE, M. DE L. AND DAVIES, N. B. 1996. Analysis of genetic differentiation of host races of the common cuckoo Cuculus canorus using mitochondrial and microsatellite DNA variation. Proc. R. Soc. B, 263, 89-96.

GIBBS, H. L., PRIOR, K. A., PARENT, C. AND WEATHERHEAD, P. J. 1997. Characterization of DNA microsatellite loci from a threatened snake, the eastern massasauga rattlesnake and their use in population studies. J. Hered. (in press).

GOUDET, J. 1995. FSTAT ver. 1.2: a computer program to calculate $F$-statistics. J. Hered., 86, 485-486.

hanotTe, O., ZANon, C., PUgh, A., GReig, C., DiXon, A. AND BURKE, T. 1994. Isolation and characterization of 
microsatellite loci in a passerine bird: the reed bunting Emberiza schoeniclus. Mol. Ecol., 3, 529-530.

LINCOLN, S. E., DALY, M. J. AND LANDER, E. S. 1991. PRIMER: A Computer Program for Automatically Selecting PCR Primers. Version 0.5. Whitehead Institute for Biomedical Research, Cambridge, MA.

McDONALD, D. B. AND POTTS, W. K. 1994. Cooperative display and relatedness among males in a lek-mating bird. Science, 266, 1030-1032.

MINCH, E., RUIZ-LinARES, A., GOLDSTEIN, D., FELDMAN, M. AND CAVALLLI-SFORZA, L. L. 1995. MICROSAT (ver. 1.4C): a computer program for calculating various statistics on microsatellite allele data. WWW: http//lotka.stanford. edu/research/distance.html

NEI, M. 1987. Molecular Evolutionary Genetics. Columbia University Press, New York.

NE1, M. AND ROYCHOUDHURY, A. K. 1974. Sampling variances of heterozygosity and genetic distance. Genetics, 76, 379-390.

PAETKAU, D. AND STROBECK, C. 1994. Microsatellite analysis of genetic variation in black bear populations. Mol. Ecol., 3, 489-495.

PEMBERTON, J. M., SLATE, J., BANCROFT, D. R., AND BARRETT, J. A. 1995. Nonamplifying alleles at microsatellite loci: a caution for parentage and population studies. Mol. Ecol., 4, 249-252.

PRIMMER, C. R., MøLleR, A. P. AND ELLEGREN, H. 1995. Resolving genetic relationships with microsatellite markers; a parentage testing system for the swallow Hirundo rustica. Mol. Ecol., 4, 493-498.

QUELlaR, D. C., STRASSMANN, J. E. AND hUGHES, C. R. 1993. Microsatellites and kinship. Trends Ecol. Evol., 8, 285-288.

RASSMANN, K., SCHLÖTTERER, C. AND TAUTZ, D. 1991. Isolation of simple-sequence loci for use in polymerase chain reaction-based DNA fingerprinting. Electrophoresis, 12, 113-118.
RAYMOND, M. AND ROUSSET, F. 1995. GENEPOP (ver. 1.2): a population genetics software for exact test and ecumenicism. J. Hered., 86, 248-249.

ROFF, D. A. AND BENTZEN, P. 1989. The statistical analysis of mitochondrial DNA polymorphisms: $\chi^{2}$ and the problem of small sample sizes. Mol. Biol. Evol., 6, 539-545.

SOKAL, R. R. AND ROHLF, F. J. 1981. Biometry: the Principles and Practice of Statistics in Biological Research, 2nd edn. W. H. Freeman, New York.

TARTOF, K. D. AND HOBBS, C. A. 1987. Improved media for growing plasmid and cosmid clones. Bethesda Res. Lab. Focus, 9, 12.

TAUTZ, D. 1989. Hypervariability of simple sequences as a general source for polymorphic DNA markers. Nucl. Acids Res., 17, 6463-6471.

TAYLOR, A. C., SHERWIN, W. B. AND WAYNE, R. K. 1994. Genetic variation of microsatellite loci in a bottlenecked species: the northern hairy-nosed wombat, Lasiorhinus krefftii. Mol. Ecol., 3, 277-290.

WEBER, J. L. 1990. Informativeness of human $(\mathrm{dC}-\mathrm{dA})_{\mathrm{n}} \cdot(\mathrm{dG}-\mathrm{dT})_{\mathrm{n}}$ polymorphisms. Genomics, 7 , 524-530.

WEBER, J. L. AND MAY, P. E. 1989. Abundant class of human DNA polymorphisms which can be typed using the polymerase chain reaction. Am. J. Hum. Genet., 44, 388-396.

WEIR, B. S. AND COCKERHAM, C. C. 1984. Estimating $F$-statistics for the analysis of population structure. Evolution, 38, 1358-1370.

YEZERINAC, S. M., WEATHERHEAD, P. J. AND BOAG, P. T. 1995. Extra-pair paternity and the opportunity for sexual selection in a socially monogamous bird (Dendroica petechia). Behav. Ecol. Sociobiol., 37, 179-188.

ZAYKIN, D. AND PUDOVKIN, A. 1993. Two programs to estimate significance of chi-squared values using pseudoprobability tests. J. Hered., 84, 152. 